\title{
The Mediating Role of Innovative Supportive Environment in the Relationship between Organizational Climate and Entrepreneurship in Sports Sciences Male Students
}

\author{
${ }^{1}$ Mohammad Keshtidar ${ }^{*}$, Fereshteh Adib Roshan, ${ }^{3}$ Mohammad Ali Sahebkaran
}

${ }^{1}$ Sport Management Department, Sport Science Faculty, University of Birjand, Birjand, Iran. ${ }^{2}$ Sport Science Faculty, Mashhad Branch, Islamic Azad University, Mashhad, Iran. ${ }^{3}$ Sport Management Department, Sport Science Faculty, Ferdowsi University, Mashhad, Iran.

\begin{abstract}
Background. Today, education of entrepreneurs is considered as one of the basic and fundamental guidelines for the comprehensive development of a country. Objectives. So the main purpose of this study is to investigate the mediating role of innovative supportive environment in the relationship between organizational climate and entrepreneurship in physical education male students in universities of Mashhad. Methods. This is a descriptive-correlational and analytical study and has been done by field method. The statistical population of the present study consists of all male students of physical education and sport sciences faculties in the city of Mashhad (1083 people). Among these students, 308 people were selected as study samples. The sampling method was cluster and simple random. Organizational climate questionnaire by Sussman \& Deep (1989) and Moghimi (2013) and entrepreneurship questionnaire of Kevin \& Slavin (1986) were used for data collection. Also for evaluating the innovative supportive environment, the questionnaire of Cheng Hava Tassi through a five-point Likert scale was used. The overall reliabilities of questionnaires were obtained respectively $89 \%, 84 \%$ and $92 \%$. The software package of spss 21 was used for descriptive statistics and the software of Liser18.5 was used for confirmatory factor analysis and structural equation modeling (SEM). Results. The study results showed that there is a positive and significant relationship between all three factors of organizational climate, entrepreneurship and innovative supportive environment (55\%). In this relationship, organizational climate (56\%) and innovative supportive environment (74\%) were effective on entrepreneurship. Conclusion. Based on research findings, it could be stated that to have Entrepreneur University in the male student part, having merely organizational space is not adequate and the space that has innovative supportive environment should govern it so in interaction with each other causes increasing entrepreneurship in these students.
\end{abstract}

KEY WORDS: Entrepreneurship, Innovative Supportive Environment, Environmental Climate, Sports Sciences Students.

\section{INTRODUCTION}

The issue of employment of university graduates in one of the most important subjects that governments are faced with. Many negative economic and social consequences that are followed by this phenomenon are crises that have engaged two groups of developing and developed countries (1). In the current situation in which Iran's economy faces the reduction in government

*. Corresponding Author:

Mohammad Keshtidar

E-mail: mkeshtidar@birjand.ac.ir 
investment, immobility and insufficient economic growth, training of entrepreneurs is of utmost importance. Therefore, in their definition of entrepreneurship, researchers consider it as the use of environmental opportunities, technical and organizational innovations and scattered financial resources to meet the economic needs of society through the creation and development of new and risky businesses. Usually, entrepreneurship has a great effect on the growth of economic and social development, improving the employment situation, business standard, controlling the inflation and reducing poverty, hence, it has been considered among the most necessary needs of society (2). In Unites States, 600-800 thousand new businesses start every year and Most of these businesses are successful and some of them fail (3). These small businesses are the foundations of employment growth. They have been permitted to be the owners of their own businesses and feel success. In this country, 200 universities teach the entrepreneurship. In this line, in 2002, Saint Louis University was raised among the top 20 universities in the USA in the field of entrepreneurship. This university expanded its activities in organizing small businesses and giving knowledge and information to young entrepreneurs. This was very much welcomed by students (4). In Iran, many research papers and theses were conducted on entrepreneurship and many researchers discussed on its importance since 2011s (5). Research results of Chamber of Commerce, Industries and Agriculture Tehran examined on rate of economic participation and rate of employment in university graduated students in 15 years and more population in years 2010 to 2013 showed that about 2.5 of them had illiterate, $31.5 \%$ of them had less than high school education, $25 \%$ had pre-university and high school education, and rest of them $(41.4 \%)$ had academic education. In other words, in 2013, more than 1 millions of unemployed people in Iran include academic graduated people and this report aims to provide an image of economic participation status and employment status in academic education sector which this process is unlike the predictions of 1404 vision document of Islamic Republic of Iran in this area. According to the above-mentioned descriptions and since the public sector and universities cannot cover the employment of all university graduates, it should be stated that one of concepts that can change economic, social and industrial situation in our country is the entrepreneurial activity and creating entrepreneurial spirit in students (6). It can also be said that entrepreneurship education has the potential to enable young people in acquiring new skills and creating employment and innovation for themselves. For example, in Tunisia, layout and design of academic curriculum make familiar the students in universities with the business and help them graduate with self-employment education (4). In fact, this environment reflects signals that individuals receive about the organizational supports of innovative and creative behaviors (7). This environment influences directly the creativity by increasing production and improving quality causes the creativity increases the quality of solutions to solve organizational issues and also helps in the creation of beneficial and cost-effective innovations. Creativity boosts the motivation, promotes individual skills and facilitates group and team functions. In these circumstances, universities start their innovation process by providing a supportive environment (8). Slinger et al. (2015) believe that entrepreneur is not an innovation, but entrepreneur under the influence of the environment in which operates can be successful or non-successful and they introduce Utrecht University in Netherlands as a university chosen this policy as its vision (9). According to this and based on some research results, universities enhance the approach of entrepreneurship by the training of it. It should be noted that these trainings are various for different disciplines. Daniela et al. (2016) conducted an investigation for the comparison of entrepreneurship educations in two groups of marketing and engineering students. The results indicate that entrepreneurship education (EE) increases the entrepreneurial intention (EI). However, entrepreneurship does not happen uniformly in all disciplines and it may need some educations tailored to a particular discipline(10).

Sharma \& Chrisman (1999) define the entrepreneurship as measures for organizational creation, rehabilitation or innovation that occur within or independent of existing organizations. Also in current competitive and market-based economy that is accompanied with quick and rapid changes and developments of international 
environment and the transition from the industrial society to an information society, entrepreneurship is considered as the engine of economic development that can lead to the economic growth and development of countries, increasing productivity and creating jobs and prosperity (11).

According to the factors motivating the students such as having a business, more control over their fate and their future, increasing the satisfaction, earning more money, leaving an inheritance for family and children in the future and given the growing acceptance of students in physical education through various academic systems (public, PNU, Azad, non-profit etc.), the necessity of the attention to environmental factors increase in universities. According to announced unemployment rate, the effectiveness of universities in the area of workforce training is notable. Not only unemployed university graduates do not provide an opportunity for the country, but also they are somehow considered as dangers and threats. On the other hand, due to basic characteristics such as human capital in from of students and academic staff, universities are proper places for knowledge-based innovation and by using this knowledge, they can begin entrepreneurship. This issue helps students having entrepreneurship characteristics and also having also passed entrepreneurship education in universities to start a business. The created business needs managing for its growth and development. If this situation makes problems for students and leads to their frustration, the result won't be different with businesses created by non-academic people and students will be disappointed and pessimist and the final result will be the duplication and waste of resources and students (12). According to the above, entering to entrepreneurship environment requires the creation of desirable structure, atmosphere and place that can provide the growth substrate of these features. Empirical evidences show that when the dominated culture in the university is based on entrepreneurship, staff can make changes in the area of their activities and offer values that distinguish the organization from its competitors and rivals so that each student can become a new entrepreneur (9). This environment can help students to have more self-confidence in increasing efficiency in their sectors and adapt themselves more simply with the existing situation and concentrate on ways to increase revenue and customer acquisition. The environment of a university that recognizes the importance of entrepreneurship supports the entrepreneurial thinking of its members. In these circumstances, teachers, employees and managers of the university feel themselves responsible for creating such an environment and encourage the entrepreneurship (9). According to what have been expressed, it can be said that the research results of Chen et al. (2016), Thorgrena et al. (2016), Letaifaa and Primard (2016) indicate that the university environment requires determining its missions and visions in order to achieve employment. The findings of these researchers show that there is a direct relationship between innovation and entrepreneurship and we need to spend longer time to achieve it $(13,14)$. Conducted studies in this domain indicate that in 2020, higher education institutions will be faced with the challenge of responding to new needs in business and work sectors (15). Researchers also stated that universities should attempt to improve knowledge triangle by promoting links between universities and businesses to enhance students' business skills. Accordingly, Elyaseiskender and GulgoulBozogiubati (2015) found in their research titled as "Comparison of entrepreneur universities and their innovation field" that using entrepreneurship has a direct relationship with innovation (16). Northring et al. (2015) investigated the relationship between the growth and using supportive infrastructures for innovative entrepreneurship. The results showed that the combination of using growth centers and technology centers can be effective on the growth of a new and innovative company. Also Karine \& Talis (2015) showed that providing new and various approaches can help students to make new businesses and apply their attitude and readiness to use these opportunities for the future and perceive it as a new tool (17). In addition to this, Wina et al. (2015) The results indicated that organizational climate has a high impact on the entrepreneurship of students (18). The research results of Stuetzera et al. (2016) indicate also the same thing. Panagiotis et al. (2016) assessed the entrepreneurship in uncertain conditions (19). They stated that in the new era, financial crises 
rise increasingly. In these circumstances, while the employment level falters, the best investment occurs in entrepreneurship. Therefore, in the present study, according to the conceptual model of research, the researches tried to investigate the impact of supportive innovative environment on the relationship between organizational climate and entrepreneurship in physical education male students in universities of Mashhad.

\section{MATERIALS AND METHODS}

Method. The study is applied in terms of method and it is descriptive and field in terms of data collection method.

Participants. The population of study consisted of male physical education students studying in the second semester academic year of 2016-2017 in Mashhad universities. Based on the inquiries from the faculty and departments of Physical Education in five Universities, including Mashhad Ferdowsi University, Islamic Azad University, PNU, Imam Reza University, and Montazeri University, the population of study was obtained 1083. To determine the sample size, PASS 11 software in accordance with classes was used that by entering the required information such as statistical power, degree of freedom, and so on, sample size was determined to be 308 people. In addition, questionnaires were distributed randomly and by distributing more questionnaires by $10 \%$ so that in case of malformed questionnaires sample size not to be reduced (Table 1).

Table 1. Description of population and sample size

\begin{tabular}{cccc}
\hline \multirow{2}{*}{ Factors } & \multicolumn{3}{c}{ Primary Eigenvalues } \\
\cline { 2 - 4 } & Name of University & Statistical population size & Sample size \\
\hline 1 & Ferdowsi & 203 & 58 \\
2 & Azad & 447 & 125 \\
3 & Payame Nour & 163 & 46 \\
4 & Imam Reza & 180 & 52 \\
5 & Montazeri & 90 & 27 \\
6 & Total & 1083 & 308 \\
\hline
\end{tabular}

Research Tools. In the present study, main tools for data collection were three standardized questionnaires. For organizational climate, the questionnaire of Lyle Sussman and Sam Deep (1989) and Moghimi (2013) was used. This questionnaire contains 25 items and appraises the 5 factors of "clarity of objective and roles", "satisfaction from rewards", "consent and agreement on procedures", "the effectiveness of communications" and "organizational climate". For the appraisal of organizational entrepreneurship, the standardized questionnaire of Kevin \& Slavin (1986) was used. This questionnaire contains 9 items and evaluated three dimensions of organizational entrepreneurship including "innovation", "being determined" and "risk taking in business and hyperactivity in competition". Also the questionnaire of innovative supportive environment is retrieved from the article "Methods of employing innovative behaviours in scientific centralized organizations" written by Cheng Hava Tassi (2011) including 5 items of "encouraging and creativity in organizations", "solving similar problems in different ways", "flexible organization" and "organizational incentives for innovators"; these items were appraised in the same way. In the end, the reliability of questionnaires was tested. The results of this test are shown in table 2.

Table 2. Reliability coefficients of research variables

\begin{tabular}{ccccc}
\hline \multirow{2}{*}{ Components } & \multicolumn{5}{c}{ Reliability coefficients } \\
\cline { 2 - 5 } & Factors & Number of items & Number of components & Alpha \\
\hline 1 & Organizational climate & 25 & 5 & $8.9 \%$ \\
2 & Entrepreneurship & 9 & 3 & $8.4 \%$ \\
3 & Innovation & 5 & 1 & $9.2 \%$ \\
\hline
\end{tabular}


Statistical Analysis. For data analysis, descriptive statistics (mean, standard deviation etc.) and inferential statistics (structural equation modeling, Spearman's correlation tests) were used in significance level of 0.05 . It should be noted that all statistical calculations were done by SPSS 21, Lisrel 8.50 software.

\section{RESULTS}

Komolgorov-Smirnov test was used for evaluating the normality of variables and the normality of data are approved. So parametric tests are used.

Diagram 1 displays the path coefficients related to structural equation model to investigate the research hypotheses.

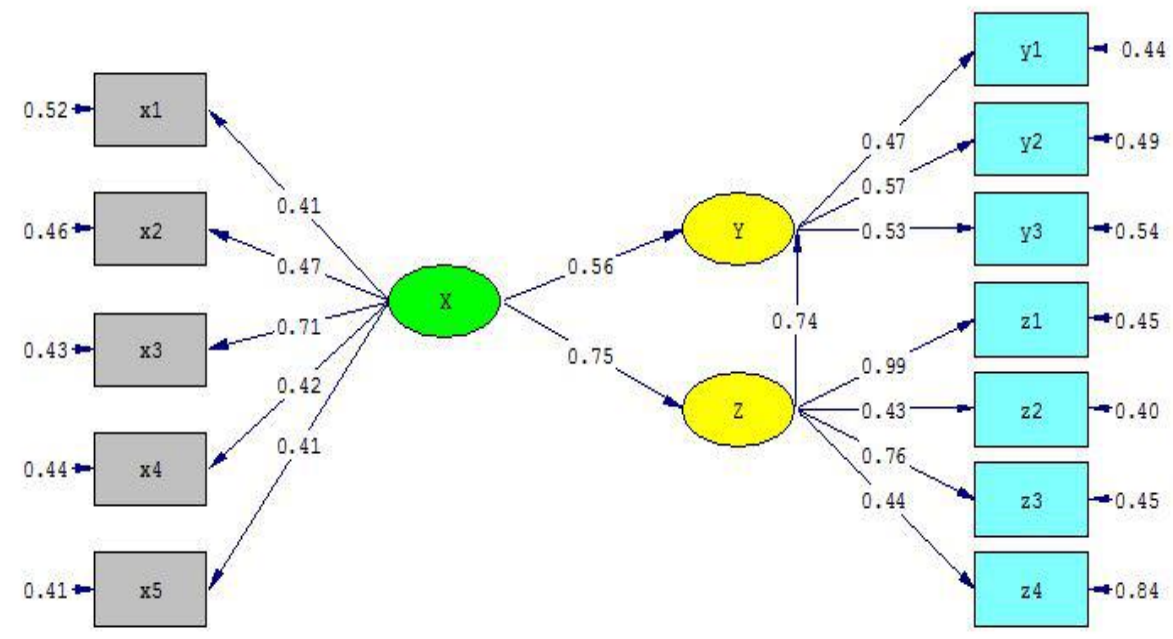

Chi-Square $=74.00, \mathrm{df}=62, \mathrm{P}-\mathrm{value}=0.00145, \mathrm{RMSEA}=0.047$

Figure 1. Factor coefficients and path coefficient of the research model. X: Organizational climate (Independent variable), y: Entrepreneurship (Dependent variable), z: Innovative and supportive environment (Mediator variable), X1: Clarity of objectives, X2: Clarity of roles, X3: Satisfaction from rewards, X4: Consent and agreement on procedures, X5: The effectiveness of communications of professional skills. Y1: Risk taking, y2: Hyperactivity in competition, y3: Innovation Z1: Creativity and incentives in the organization, z2: Permission of solving similar problems in different ways, z3: Searching innovative ideas, z4: flexible organization and z5: Organizational encouragement for innovators.

Given that the values of t statistic of all load factors are above 1.96, so it can be concluded that selected questions provide appropriate factor structures for measuring the studied variables and dimensions in the research model. In table 3, the values of fitting indices are shown. The amount of RMESA is 0.047 and since it's lower than 0.08 , it shows that the model is acceptable. The value of relative chi-square, division of chi-square on freedom degree is 1.19 and between 1 to 3 , also the values of indices of AGFI, GFI, IFI, CFI and NFI are more than 0.9. In overall, the values of indices are consistent with their interpretive criteria; and confirmatory factor analysis approves the structure of studied dimensions in research model.

Table 3. Fitting indices of research model

\begin{tabular}{ccccccc}
\hline$\chi 2 / \mathrm{df}$ & RMSEA & NFI & CFI & IFI & GFI & AGFI \\
\hline 1.19 & 0.047 & 0.93 & 0.92 & 0.94 & 0.92 & 0.91 \\
\hline
\end{tabular}

RMESA: Root mean squared error of approximation, AGFI: Adjusted Goodness of Fit Index, GFI: Goodness of Fit Index, IFI: Incremental Fit Index, CFI: Comparative Fit Index, NFI: Normal Fit Index. 
According to the approval of the questions related to questionnaire factors, in the next part, the hypotheses of research will be tested and evaluated. According to figures 1 , the summary of obtained results from the fitted model is shown in table 3. As mentioned, paths with $\mathrm{t}$ statistic upper than 1.96 or lower than -1.96 are significant.

Testing of the first hypothesis. According to table 4, path coefficient between organizational climate and entrepreneurship is 0.56 . This is a positive amount. The related t-value is 2.09 and more than 1.96. Therefore, with the confidence level of $95 \%$, it can be concluded that this path coefficient is significant in error level of 0.05 and the existence of a significant, direct and positive relationship between organizational climate and entrepreneurship is approved.

Testing of the second hypothesis. According to table 4, path coefficient between organizational climate and entrepreneurship is 0.75 . According to significance value reported in Table 4 , it could be concluded that there is significant and positive relationship between two variables.

Testing of the third hypothesis. According to table 4, path coefficient between organizational climate and entrepreneurship is 0.74 . According to significance value reported in Table 4, it could be concluded that there is significant and positive relationship between two variables.

Table 4. Results for testing research hypotheses

\begin{tabular}{ccccc}
\hline Hypothesis & Tested relationship & Path coefficient & T statistic & Result \\
\hline First & $\begin{array}{c}\text { Organizational climate } \\
\text { Entrepreneurship }\end{array}$ & 0.56 & 2.09 & Significant \\
\hline Second & $\begin{array}{c}\text { Organizational climate } \rightarrow \text { Innovative \& } \\
\text { supportive environment }\end{array}$ & 0.75 & 2.32 & Significant \\
\hline Third & $\begin{array}{c}\text { Innovative \& supportive environment } \rightarrow \\
\text { Entrepreneurship }\end{array}$ & 0.74 & 4.32 & Significant \\
\hline Forth & $\begin{array}{c}\text { Organizational climate } \rightarrow \text { Innovative \& } \\
\text { supportive environment } \\
\rightarrow \text { Entrepreneurship }\end{array}$ & $0.74 * 0.75=0.555$ & ---- & Significant \\
\hline
\end{tabular}

Testing of the forth hypothesis. Organizational climate has a positive and significant impact on entrepreneurship of students through the innovative and supportive environment. This hypothesis investigates the mediator impact of innovative supportive environment (mediator variable) in the relationship between the independent variable of "organizational climate" and dependent variable of "entrepreneurship of students". For examining the indirect impacts of independent variable on dependent variable, the following provisions first need to be established. The first condition is the confirmation of the significance of relationship between independent and mediator variables and the second condition is the approval of the significance of the relationship between mediator and dependent variables. Then, in case of the above conditions, the path coefficient of indirect relationship is obtained by the multiplication of path coefficient of relationship between independent and mediator variables and path coefficient of the relationship between dependent and mediator variables. In the following section, these conditions will be examined for each independent variable. According to table 4, it is observed that "organizational climate" has a positive and significant impact on "innovative and supportive environment" with path coefficient of 0.75 and "innovative and supportive environment" has a positive and significant impact on "entrepreneurship of students" with path coefficient of 0.74 . So first and second conditions are established and the path coefficient of the indirect relationship between organizational climate and entrepreneurship through the mediator variable of innovative supportive environment is calculated as follows:

$$
0.75 * 0.75=0.555
$$

Therefore, it can be concluded that organizational climate has a positive and significant impact on the entrepreneurship of students through innovative and supportive environment and the 4th hypothesis of research is conformed. 


\section{DISCUSSION}

Entrepreneurship is an important and essential factor for economic and social growth and development in today's world. During the process of entrepreneurship, new opportunities will be created for the employment. In the present research, we investigated the role of an innovative and supportive environment in creating appropriate conditions in organizations for sports entrepreneurship and creating new opportunities for employment. The statistical population of this research consists of all male students in physical education in the universities of Mashhad during the academic year of (2015-2016). Before responding to this question, we explore the hypotheses of research. In the approval of the significance of $1^{\text {st }}$ hypothesis with path coefficient of 0.56 , it has been determined that there is a significant relationship between organizational climate and entrepreneurship of students. Entrepreneurship is one of the ways for universities to meet environmental requirements; and the organizational climate is a relatively stable set of perceptions of organizational members. This perception influences the feelings, attitudes and behaviors of individuals in the workplace. Boldon also believes that organizational climate is an environment in which people work and reflects the attitude of the staff and the organization's management style. Now, education should be done with more speed and better quality than in the past. For achieving this objective, advanced equipment of today should be used in order to foster creativity and critical thinking. These findings are consistent with the studies of Stuetzera et al. (2016) and Wina et al. (2015) $(18,19)$.

The second hypothesis indicates a significant relationship between organizational climate and innovative supportive environment with path coefficient of 0.75 and in significance level of 0.05 . Organizational factor is one of the dimensions that indicate the ruling social space in any organization and innovation is one of the ways for increasing competitive advantages and is often considered as one of the most important strategic approaches of organizations to achieve long-term successes; it has a significant effect on risky affairs. It seems that the existence of an appropriate environment can assume the role of a permanent stimulus and conduct the staff behavior in the direction of innovation. Therefore, it can be said that if an organization with an appropriate environment for innovation faces a crisis, it is possible to overcome the crisis by drawing the attention of employees to the solution of the problem. But in an organization with negative atmosphere, drawing these attentions takes a very long time. In organizations in which there exists a coherent and pro-innovation organizational climate, all members are committed and dedicated to new innovations are review common current initiatives in organizations. In such organizations, organizational climate influences the employees with the objective of supporting risks that are natural consequences of the implementation of innovations in the organization. These findings are consistent with the study results of Balan \& Lindsay and Slinger et al. (2015) (20).

The results of third hypothesis indicate that environment can act as a monitor that receives signs about the support of organizations from innovative and creative behaviors. These behaviors include organizational support mechanism that leads innovative employees to using their creative abilities and talents for doing entrepreneurial activities. This mechanism is also a stimulus for the motivation of employees and using their maximum ability and productivity for innovative actions. The availability of such an environment is considered as joint assets of individuals and organizations and its existence is a function of organizational structure, membership of individuals and their effort to understand the organization's support (21). Education of students in such an environment creates a high entrepreneurial spirit in them and helps them to overcome their fear to the environment and their absence. These findings are consistent with research results of Thirgrena et al. (2016) and Ben \& Primard (2016).

The confirmation of the firth hypothesis depended on two conditions. The first condition was the approval of the existence of a significant relationship between independent and mediator variables and the second condition was the confirmation of the existence of a significant relationship between dependent and mediator variables. Since two mentioned conditions were established and the path coefficient of indirect 
relationship between organizational climate and entrepreneurship of students through the mediator variable of innovative and supportive environment is $55 \%$, so the $4^{\text {th }}$ hypothesis was approved.

\section{CONCLUSION}

It is obvious that the weakness of university nature in communicating with other universities and small and large businesses can be considered as the main causes of reduction of the ability of universities in the field of creation and innovation. In this case, by removing the mentioned barriers, it is possible to have a lot of important and basic progress in order to strengthen the capacity of innovation in universities and change work structures and processes. In overall, by creating supportive structures for entrepreneurship in universities and providing proper environments, it is hoped that the level of innovation in universities will be enhanced. According to research results, it can be stated that for having entrepreneur university in male students sector, having organizational space is not adequate and an innovative supportive space should govern it so that in interaction with each other causes increasing entrepreneurship among these students.

\section{APPLICABLE REMARKS}

- Entrepreneurship topics to be one of the compulsory courses in university both theoretically and practically.

- Holding entrepreneurship festivals and workshops with the cooperation of owners of the industries.

- Businesses of male sports science graduates of various universities of the country can explain the appropriate results for planners of the country.

- It is recommended for researchers to conduct studies on the comparative investigation of employment of domestic and foreign sports science university graduates.

\section{REFERENCES}

1. Roig-Tierno N, Alcázar J, Ribeiro-Navarrete S. Use of infrastructures to support innovative entrepreneurship and business growth. Journal of Business Research. 2015;68(11):2290-4.

2. Dadgar Y GA. Analysis of entrepreneurship in the past 70 years in Iran”. Case study: The performance of a typical entrepreneur. Quarterly of Economic researches. 2010;2:61-90.

3. Premand P, Brodmann S, Almeida R, Grun R, Barouni M. Entrepreneurship education and entry into selfemployment among university graduates. World Development. 2016;77:311-27.

4. Petrakis PE, Kostis PC, Kafka KI. Secular stagnation, faltering innovation, and high uncertainty: New-era entrepreneurship appraisal using knowledge-based thinking. Journal of Business Research. 2016;69(5):1909-13.

5. al Te. Providing a regression model for organizational climate and organizational entrepreneurship in physical education faculties in Iran. Quarterly of research in the humanities. 2009;22:97-116.

6. Başçı ES, Alkan RM. Entrepreneurship education at universities: suggestion for a model using financial support. Procedia-Social and Behavioral Sciences. 2015;195:856-61.

7. Tsai C. Innovative behaviors between employment modes in knowledge intensive organizations. International Journal of Humanities and Social Science. 2011;1(6):153-62.

8. Johne FA, Snelson PA. Success factors in product innovation: A selective review of the literature. Journal of product innovation management. 1988;5(2):114-28.

9. Jansen S, van de Zande T, Brinkkemper S, Stam E, Varma V. How education, stimulation, and incubation encourage student entrepreneurship: Observations from MIT, IIIT, and Utrecht University. The International Journal of Management Education. 2015;13(2):170-81.

10. Maresch D, Harms R, Kailer N, Wimmer-Wurm B. The impact of entrepreneurship education on the entrepreneurial intention of students in science and engineering versus business studies university programs. Technological forecasting and social change. 2016;104:172-9.

11. Sharma P, Chrisman SJJ. Toward a reconciliation of the definitional issues in the field of corporate entrepreneurship. Entrepreneurship: Springer; 2007. p. 83-103.

12. Robinson D. Economic development from the state and local perspective: Case studies and public policy debates: Springer; 2014. 
13. Hu H, Huang T, Zeng Q, Zhang S. The role of institutional entrepreneurship in building digital ecosystem: A case study of Red Collar Group (RCG). International Journal of Information Management. 2016;36(3):496-9.

14. Letaifa SB, Goglio-Primard K. How does institutional context shape entrepreneurship conceptualizations? Journal of Business Research. 2016;69(11):5128-34.

15. Pérez CR, Cubero LN. Universities with Added Value: Employability and Innovative Entrepreneurship. ProcediaSocial and Behavioral Sciences. 2014;139:65-71.

16. İskender E, Batı GB. Comparing Turkish Universities Entrepreneurship and Innovativeness Index's Rankings with Sentiment Analysis Results on Social Media. Procedia-Social and Behavioral Sciences. 2015;195:1543-52.

17. Oganisjana K, Laizans T. Opportunity-oriented problem-based learning for enhancing entrepreneurship of university students. Procedia-Social and Behavioral Sciences. 2015;213:135-41.

18. Christina W, Purwoko H, Kusumowidagdo A. The role of entrepreneur in residence towards the students' entrepreneurial performance: a study of entrepreneurship learning process at Ciputra University, Indonesia. Procedia-Social and Behavioral Sciences. 2015;211:972-6.

19. Stuetzer M, Obschonka M, Audretsch DB, Wyrwich M, Rentfrow PJ, Coombes M, et al. Industry structure, entrepreneurship, and culture: An empirical analysis using historical coalfields. European Economic Review. 2016;86:52-72.

20. Balan P, Lindsay NJ. Innovation capability and entrepreneurial orientation dimensions for Australian hotels: Cooperative Research Centre for Sustainable Tourism; 2009.

21. Wu C-W. Global entrepreneurship and innovation in management: Comparing MRA/SEM versus fuzzy-set QCA theory creation, data analysis, and findings. Elsevier; 2016. 